\title{
Pragmatic Competence for L2 Learners: The Case of Maybe, Perhaps, and Possibly as Hedging Terms
}

\author{
Fahad Alqurashi \\ Department of English, Umm Al-Qura University, Makkah, Saudi Arabia
}

\begin{abstract}
The construct of hedging is a significant part of the native speaker's intuition used to indicate different degrees of un/certainty and mark various levels of likelihood. This paper explores the use of three sentence adverbs, maybe, perhaps, and possibly, in terms of their pragmatic differences in spite of the great deal of overlap in their semantic structure when used to hedge propositions. The use of the three hedging devices is highly affected by three parameters the: formality, positiveness, and possibility. In addition, the three hedging devices behave similarly in the sense that they occur in direct questions but not in imperatives or comparative structures and have no corresponding negative forms. They are different in being derived from an adjective or rephrased with a cognate word and occurring initially in requests or after intensifiers. Appropriate use of hedging is among the difficult aspects of learning a second/foreign language even for those who achieved an advanced level of proficiency in $\mathrm{L} 2$.
\end{abstract}

Index Terms - hedging, pragmatic competence, effective communication, social \& cultural context

\section{INTRODUCTION}

Hedging terms, or hedges, are linguistic items used to communication, spoken and written, more effective and meaningful in all spheres of life. In his seminal work, Hedges: A Study in Meaning Criteria and the Logic of Fuzzy Concepts, published in the early 1970s, G. Lakoff discussed the logical properties of hedging terms and phrases "to make things fuzzier or less fuzzy" (Lakoff, 1972, p. 195). This definition of hedges includes a wide range of expressions cutting across parts of speech that both weaken the commitment to a proposition and also intensify that commitment. The truth and falsity of speech or discourse, according to Lakoff, are a matter of degree, and hedging terms make natural language sentences more/less true or more/less false (Itani, 1995). Many researchers questioned the ways that writers and speakers give opinions, express a viewpoint, or make a judgment and attempted to account for such meanings in a number of ways and described these varied linguistic resources as metadiscourse (Vande Kopple, 1985; Crismore, 1989), stance (Biber and Finegan, 1989), attitude (Halliday, 1994), epistemic modality (Hyland, 1998), evaluation (Thompson, 2000), and appraisal (Martin, 2000; White, 2003).

Employing hedging terms is part of language use that reflects a high degree of efficiency in social communication because hedging terms add crucial aspects to how we understand each other and provide additional value that makes speech and discourse more interactive. Several schools of thought consider language use directly related to specific social, cultural and institutional contexts. Approaches like systemic functional and social constructionist have sought to elaborate how effective communication strategies can help exchanging information more successfully and to explain the roles different linguistic features play in assisting us understand an input and make feedback (Hyland, 2005). An essential aspect that makes communication effective and successful is pragmatic competence that has been defined as "the ability to communicate your intended message with all its nuances in any socio-cultural context and to interpret the message of your interlocutor as it was intended" (Fraser, 2010, p. 15). Pragmatic competence has been viewed as a distinct construct that is significant to determine and understand implied meaning through the use of contextual, sociolinguistic, sociocultural, psychological, and rhetorical factors (Purpura, 2004).

The importance of pragmatic competence as a key to effective communication has gained increasing attention in the field of teaching foreign languages in the sense that having a good command of linguistic knowledge in target language would not be enough to serve the L2 learner's communicative needs. In other words, having a broad vocabulary, errorless pronunciation and a profound knowledge of grammatical structures of the target language is not enough to communicate in that language successfully and effectively because linguistic knowledge only doesn't help L2 learners to make judgments in terms of what is socially appropriate when communicating with particular interlocutors in particular situations (Brubæk, 2013). In many settings of teaching English as a foreign language pragmatic competence is often overlooked while grammatical competence is explicitly taught and developed which produces L2 learners who may produce grammatically flawless speech, but because of the lack pragmatic competence, they nonetheless fail to achieve their communicative aims efficiently. Consequently, pragmatic competence should be given more emphasis in language education because of its value and effect in communication success. 
One area where EFL learners face serious problems because of the lack of pragmatic competence is that of hedging. This paper discusses the semantic structure of three hedging terms; maybe, perhaps, and possibly, introduces how the three terms are used in concrete situations, compares and contrasts these terms to figure out the circumstances under which each one of them can be used, and illustrates the similarities and differences of their pragmatic value and effect in constructing the meaning. Examples in this paper were taken from Newspaper Source Database Information, a database that provides full text for hundreds of international newspapers.

\section{Pragmatic StRUCture}

Hedging terms, including maybe, perhaps, and possibly, are used to indicate the degree of truth of a given statement and function to raise or drop the values in the range of the truth scale. They have been studied from different perspectives and classified into two categories according to their functions in the sentence: approximators and shields. According to Prince et al. (1982, p. 86) "Approximators contribute to the semantics by indicating some markedness, i.e., non-prototypicalness with respect to class membership, while shields affect the pragmatics by inducing implicatures conveying markedness with respect to the speaker commitment." More specifically, those hedges that modify the truthconditions of an expression and provide fuzziness within the prepositional content are called approximators and are used to indicate the speaker's commitment to the truth of the proposition s/he is conveying. The other class of hedges places fuzziness in the relationship between the prepositional content and the speaker and does not affect the truthconditions of an utterance. Hedges of this class are called shields and are incorporated in sentences to point out that the speaker is not fully committed to the truth of the proposition conveyed (Fraser, 2010).

Hedging terms can occur in different places in sentences. They can precede the figure in cases like: 'almost perfect' or 'close to the saturation point.' They can follow the figure such as ' $50 \%$ or so' or 'ten students or more'. In some cases we find more than one hedging term in the same phrase like 'about five minutes or so' and 'around twelve boxes or more.' The terms maybe, perhaps, and possibly are hedging terms that occur fairly frequently in everyday speech. Investigating the subtle differences among the three terms is significant in the sense that the relationship among maybe, perhaps, and possibly hasn't been defined very well in grammar books. Their pragmatic functions and discourse meanings in different situations haven't been explained in EFL and ESL textbooks. This topic is important for English learners in the sense that mastering the differences among the three words will enhance their language proficiency and improve their communication skills.

One of the problems that EFL and ESL students have in distinguishing the meanings of the three terms maybe, perhaps, and possibly is that dictionary definitions are circular at best in the sense that they define them in terms of each other. For example, the word maybe is defined in the Oxford English Dictionary as an adverb that means 'possibly' or 'perhaps.' Perhaps is an adverb that is defined as "a word qualifying a statement so as to express possibility with uncertainty: it may be, possibly; = perchance." The word possibly is defined as an adverb that is "derived from the adjective possible. When something is possible that means it "may be (i.e. is capable of being); that may or can exist, be done, or happen." The word possibly is defined as "in a possible manner; according to what may or can be (in the nature of things) by any existing power or means; within the range of possibility." Merriam Webster Dictionary defines maybe as an adverb that means 'perhaps'. Perhaps is also defined as 'maybe or possibly but not certainly.' The meanings we find for possibly are "in a possible manner, by any possibility, by merest chance, and perhaps."Needless to say, defining the three words in terms of each other doesn't help much. The meanings given for the three words are circular and of no help to figure out how they are different. This kind of defining words does not provide us with highly revealing clues about their meaning. It provides us with only a general sense of the meaning that helps to understand the main idea.

The three hedging terms, maybe, perhaps, and possibly make things 'fuzzier' in different ways. The following examples illustrate this point:

1) Here's a new theory: Maybe Ryan Leaf is a unifying force for the San Diego Chargers.

In this sentence there is a sense of sarcasm derived from the phrase 'Here's a new theory.' It implies that the idea that Ryan Leaf is a good player and that the team needs him has been around for a while but let's look again; we might have been wrong. Although the speaker thinks strongly that this player, Ryan Leaf, is really a unifying force for the team, he couldn't directly impose this opinion. Instead, he is promoting this opinion by making a kind of suggestion. It is a novel idea that might not be 100 percent correct but it could be. Maybe here is included in a declarative sentence and more of giving an opinion that contains possibility. Using perhaps here would have a suggesting tone in the sense that maybe nobody thought about this idea before. Using possibly sounds more serious and encouraging for the idea that it is possible this player is good.

2) John Stockton pushed the replay button Sunday afternoon, taking over in the fourth quarter of a tight game, just like he has many times in the past. The master of the pick-and-roll, Stockton ran it to perfection against the Sacramento Kings. He scored 12 of his 20 points in the fourth quarter and also handed out four assists, rallying the Utah Jazz in the fourth quarter for a 94-90 victory. "John has been doing that for years, you kind of take it for granted and maybe other teams do as well," said Karl Malone, who had 24 points, nine rebounds and six assists. "He made big shot after big shot."

This example is inside a quotation. Therefore, it is informal and colloquial. The situation seems very close to the speaker and shows doubt on his part. Maybe here indicates that he is not sure of which team that might take it for 
granted or weather other teams would take it for granted or not. Perhaps and possibly in this context don't show as much doubt as possibility that other teams took for granted that this player, John Stockton, did it many times. Perhaps is the most certain among the three words in this context while possibly indicates a situation that has a chance of existing without having any tie to the speaker.

3) Former NHLer Brett Lindros, brother of star forward Eric Lindros, was in fair condition Sunday after an early morning snowmobile accident in cottage country near Parry Sound, ant. His father, Carl Lindros, said "the former New York Islander had internal injuries and maybe a broken rib or two."

Maybe is an informal, colloquial, and tentative word that shows that the reporter is not certain about how much injury that player has. The reporter is sure that the player had internal injuries but he is not sure if the player had broken ribs or not. The reporter knows for sure that they are looking for something but they haven't found it yet. Using maybe here indicates that he is not sure about the exact amount of the injury. Maybe separates the internal injuries and the broken ribs because internal injuries makes it sound much more serious and much more exact. Maybe here takes broken ribs away from the internal injuries. The statement "maybe a broken rib or two" makes it less sure and gives the impression that the internal injuries are worse than the broken ribs. Perhaps is a stronger and more formal term than maybe but not definite in this context. If it was used here it would give the impression that the player is more likely to have had broken ribs. Using possibly indicates that the reporter doesn't know if they are looking for broken ribs or not. Possibly here connects the situation more to the internal injuries and makes the statement "a broken rib or two" a kind of explanation to what the internal injuries might be.

4) "Next year, thank goodness, we're going to have a different president," said Senate Majority Leader Trent

Lott, R-Miss. "Hopefully we'll have a better atmosphere around here. Maybe we can work together."

Using maybe adds a hint of sarcasm to the context. In fact they should be able to work together anyway because they are professional politicians. Senate Majority Leader Trent Lott doesn't want to move ahead of himself and make a promise to work with the next president. Instead, he made a statement to convey some possibility for better cooperation. It is evident that the speaker is fed up with the current atmosphere from which we understand that they did not work together well. The focus is not on the ability to work together but a subtle insult with an ironic maybe. Replacing maybe with perhaps would sound more positive in tone which makes it less appropriate for expressing sarcasm. Using possibly changes the emotional value by expecting some hope for something better in response to the conflict in the Senate House.

5) The Crisis That Maybe Cried Wolf.

This is a newspaper headline that is derived from the children's story 'the boy who cried wolf.' Maybe places uncertainty on the statement. The noun phrase 'the crisis' is a serious phrase but the use of maybe here is more of slang because it reveals the proposition through the sense of humor by referring to the famous children story. Perhaps doesn't fit here because it sounds too formal. Possibly doesn't fit either because it indicates remote possibility.

6) Ford Motor Co. has been sued again over an allegedly defective ignition part that can cause vehicles to stall while driving. The latest suit was filed Monday in St. Louis Circuit Court by Michael Memos, director of human resources at St. Louis University. Memos' attorneys hope to win class-action status for their suit so that they can represent others with such complaints from throughout Missouri and perhaps beyond. Similar suits have already been filed in at least six other states.

Using perhaps indicates possibility because there isn't enough information available and more research is needed. Perhaps here is presenting an option or goal to go beyond Missouri and functioning to keep open possibilities of these complaints. It leaves the door open to have more complaints from other states. Maybe and possibly fit here but they are not as good as perhaps in this context. Maybe does not sound as encouraging and enthusiastic as perhaps because of its negative connotation. Possibly would indicate that the situation is shaky and there is much less possibility that there are complaints from other states.

7) Lake Vostok, the largest of the polar lakes, lies beneath more than two miles (three kilometers) office and is thought to have a liquid pool with a depth of about 3,000 feet (900 meters), said John C. Priscu of Montana State University. In a report Saturday to the national meeting of the American Association for the Advancement of Science, Priscu said the thick blanket of ice has sealed the lake's waters from the open air for perhaps 20 million years.

This is a scientific context in which perhaps is dealing with a number that is not close to exactness. This figure, 20 million years, is a large number for which he has no precise way to determine its correctness. The use of perhaps shows a degree of certainty based on some scientific data that this phenomenon has been for 20 million years. However, there is no solid evidence to prove it but this is what he thinks. Even though perhaps is the strongest among the three words in terms of making a statement, it indicates that there is a great range for error in this analysis. Using maybe sounds less positive about the number and makes the statement less certain. Maybe serves in this context to give a sense of estimating and sounds a little too personal. Possibly indicates that there is a possibility or chance of occurrence but we don't know and we can't prove it.

8) In two years, Victoria Keenan went from victim to victor over the Aryan Nations. Her lawsuit bankrupted the neo-Nazis, and last week she took possession of the hate group's 20-acre compound, which housed and trained some of the nation's most violent racists and anti-Semites. "We hope to get the evilness out of there and 
turn it around to something positive," said Keenan' son, Jason. They said they plan to sell the compound, perhaps to a human rights organization.

They are definitely going to sell it but they do not know to whom. Using perhaps indicates that they might want to sell it to a human rights organization because they think it might be a fair trade but the context does not sound that there is such an organization interested in buying it right now. It shows a desire and gives a sense of confidence that this thing can really happen. Maybe adds more uncertainty to the situation in the sense that they look at the possibilities around them. If they find a human rights organization that is interested in buying the compound, they might sell it to that organization. Possibly gives a stronger sense about the possibility of selling the compound to a human rights organization and indicates that this chance is out there but they have not contacted anybody yet.

9) A man named Leo Anderson asked perhaps the hardest question of Tuesday night's third and final presidential debate, scolding Texas Gov. Bush for appearing "overly proud" when he spoke in the previous debate of enforcing the death penalty.

The reporter thinks that this particular question was the hardest but there is still no

way to determine or judge precisely. By using perhaps he is making a kind of speculation and showing his opinion that he favors that particular question, but he doesn't make it clear in order not to leave anybody else out of it. In other words perhaps adds some formal flavor by considering other people's opinions that are different from the speaker's opinion about the hardest question. Possibly is close to perhaps in this context but it indicates less possibility. Using maybe would indicate almost the same idea with even less possibility because it neutral in such a context and doesn't carry a sense of positiveness.

10) With the success of the Sydney Games perhaps still fresh in their minds, a survey released Tuesday showed that 68 per cent of Canadians polled were in favor of Toronto's bid to host the 2008 Summer Olympics.

Perhaps in this sentence is a part of a cause and effect relationship. People supported Toronto's bid to host the 2008 Summer Olympics because they were happy for the success of the Sydney Games. The introductory phrase that contains perhaps in it offers a rationale for the context of the rest of the sentence. Using maybe here is a little bit funny and doesn't sound right because the reporter is guessing too much without having enough information with which he can make the right prediction. Possibly is more usable in this context but it indicates less possibility.

11) As Wertime writes, his father, Theodore Wertime, was multitalented: an accomplished violist and violinist, a member of the Office of Strategic Services in India and China, and later a cultural attaché in Iran and Greece who possibly doubled as a CIA agent.

There is a big claim and serious rumor here. It sounds that the writer and possibly other people have a personal belief that Theodore Wertime is really a CIA agent but he cannot prove it because he doesn't have enough evidence. So he prefers to be on the safe side and not to introduce the idea because it is dangerous. The available alternative is to hedge it through the use of possibly. Possibly in this context indicates less possibility than maybe or perhaps. Perhaps comes next in the sense that it is more appropriate to sound more sure but still there is not enough evidence derived from this assumption. Maybe conveys more possibility here as if the writer could confirm what he is talking about.

12) An expert team from Canada, the United States and Mexico is expected to tell soon if there is mad cow disease in Brazil, whose beef products are banned in the three countries. The animal quarantine authorities of the three countries issued a joint statement here Sunday that their joint technical group will issue a technical appraisal on the disease having possibly occurred in Brazil as soon as possible.

This is a sentence in which possibly is used to not show doubt at all, but to show possibility or chance. Possibly here shows that they don't know for sure because the situation is still open. They don't want to make it look like they know. Possibly has a neutral flavor here. It indicates that some people think the mad cow disease occurred but the joint team hasn't decided. Possibly means other people think it did occur or may have occurred. The group isn't sure and they are not committing themselves one way or the other. The reason why the team is there is because some people think there is a good possibility that there is a mad cow disease there. The job of the team is checking to confirm or refute such allegations. The team is not sure and the reporter is not sure either. There is a s strong enough chance that it occurred, so they are investigating it. If there were a low possibility maybe they wouldn't bother. Maybe and perhaps make them not real sure and they do not have evidence. They are going in there basically to find out. Maybe makes the process of investigation start from knowing nothing and functions to show doubt and lack of certainty about the occurrence of the disease. Perhaps sounds they have initial information, but they need more to be able tell exactly this disease occurred or not. It seems that the speaker is leaning towards there is a disease

13) Mining entrepreneur Robert Friedland is clearly hoping that, by taking on one of BHP's cast- offs, he is about to repeat his Voisey's Bay nickel coup. His Ivanhoe Mines, based in Canada but also listed here, announced it might be on the track of a huge copper-gold deposit in Mongolia, possibly as big as 750 million tons.

Possibly here doesn't indicate a gap at all on the part of the speaker. Rather, it indicates a situation that has a good lighting on it being true. It offers a possibility in the sense that it is a situation that might exist. Possibly in this context provides a kind of hopeful speculation and optimistic anticipation about the amount of the discovered deposit. It is not a fact that the copper-gold deposit in Mongolia is 750 million tons but it is possible. Possibly is used here in a formal context dealing specifically with businesses. It gives a feeling about how big the copper-gold deposit is. Using maybe in 
this sentence changes the meaning significantly in the sense that the writer is very much uncertain about how big the copper-gold deposit is. Because there is not enough evidence, the writer here cannot tell exactly how much that amount is but he is speculating. The term perhaps gives some kind of confidence that this is the exact number and gives some impression that there is information that made them convinced about the amount and that it is almost 750 million tons.

14) Exactly who will be playing for the Big East basketball title this upcoming season is impossible to project.

From defending champion St. John's to preseason favorites Connecticut and Seton Hall, the league is full of freshmen, players who are possibly more talented than their predecessors but definitely less experienced.

The speaker is giving an educated guess here in the sense that he thinks this is the case because of the little bit of knowledge he has. There is a kind of uncertainty about the proposition that those freshmen have more talent in playing basketball than their predecessors. The use of possibly reflects this kind of uncertainty because he hasn't seen them in action. Using perhaps would give a weaker assumption that those players are more talented because it is a formal term that is not usually used in such a context very often. Using maybe would change the meaning by expressing less chance that those players are talented and would make experience more important than talent.

15) Who could possibly still be in favor of the Electoral College after this election?

This is an example in which the word possibly occurs in a question. By using possibly in this context the speaker sounds confident that almost everybody is against the Electoral College. This is an excellent example that shows how possibly indicates only little possibility. The speaker chose possibly to indicate that there are only a few people who might still support the Electoral College. Neither maybe nor perhaps fit here because they would add more opportunity to the sentence which goes against the wish of the speaker.

From the above examples we conclude that maybe, perhaps, and possibly are sentence adverbs that function as hedging terms to express possibility and indicate likelihood of propositions in sentences. Sentence adverbs, in general, occupy an important position in English vocabulary and grammar. The three terms have high frequency of occurrence in everyday language and have great variation of usage in different situations.

Structurally and functionally, maybe, perhaps, and possibly share some characteristics and differ with respect to some other characteristics. Three parameters affected the use of the three adverbs in the examples above: formality, positiveness, and possibility. Maybe is an informal term that is used to hold back certainty in a negative way and indicates negative connotation. Perhaps is a formal term that indicates a positive connotation. The two terms seem to behave similarly when it comes to reveal possibility. The possibility level of propositions that include maybe or perhaps may go up, roughly speaking, to 30-50\%. Possibly is a term that is less formal and positive than perhaps but more formal and positive than maybe. Possibly indicates more remote possibility whose chance of occurrence may not exceed $10 \%$ which indicates it is not so established.

The adverbs maybe and perhaps are neutral terms that provide degrees of possibility to confirm or refute a proposition. They come in the middle of the scale of un/certainty in the sense that they occupy the central point between full certainty and full uncertainty. Propositions expressed with perhaps are more positive than those expressed with maybe. Perhaps conveys little more possibility than maybe because it is more formal and is used more in writing. A quick look at the frequency of usage of the three terms in a search database that gives abstracts like Eric shows the following results: perhaps occurs 2478 times, possibly occurs 1556 times, and maybe occurs only 148 times.

Maybe is less certain than perhaps. A sentence with maybe doesn't provide the addressee with an adequate amount of information to let him know. This is the reason why maybe is incorporated when exams of math and logic are designed. Possibly is a neutral term according to the formality and positiveness scales. Therefore, propositions expressed with possibly less formal and positive than those expressed with perhaps but more formal and positive than those expressed with maybe. However, possibly indicates less possibility than both maybe and perhaps. Propositions expressed with possibly have less chance and less likelihood to come true than those expressed with maybe.

The following grid illustrates theses variations:

\begin{tabular}{|l|l|l|l|}
\hline Adverb & Formality & Positiveness & Possibility \\
\hline Maybe & - & - & \multirow{2}{*}{$30-50 \%$} \\
\hline Perhaps & + & + & $10 \%$ \\
\hline Possibly & Neutral & Neutral & $10 \%$ \\
\hline
\end{tabular}

Along with the semantic differences the terms maybe, perhaps, and possibly have other types of differences. Morphologically speaking, possibly is an adverb that is derived from the adjective possible. Maybe and perhaps are not derived from adjectives. This morphological difference makes the sentence that has possibly in it 'rephrasable' by changing the adverb possibly to the adjective possible, along with some other changes, and give the same meaning. Sentences with maybe and perhaps cannot be rephrased the same way. The following two sentences make a good example of the rephrasing process that produces synonymous sentences:

16) Students feel that possibly the teacher wanted to trick them in the quiz.

17) Students feel that it is possible that the teacher wanted to trick them in the quiz.

There is another interesting point about the morphology of maybe, perhaps, and possibly that marks some similarity. The three terms do not have negative corresponding forms with negation prefixes. This may not be surprising for maybe and perhaps but it is surprising for possibly. The adverb possibly is derived from the adjective possible which has a 
negative corresponding form. The negative prefix im can precede possible to make the adjective impossible that gives the opposite meaning. This is not the case with the adverb possibly. It does not take any negative prefix to form an opposite meaning.

Occurring after intensifying terms such as 'very' and 'quite' is another difference among maybe, perhaps, and possibly. Maybe and perhaps cannot occur after intensifiers for reasons related to their basic meanings. Consider the following examples:

$18) *$ This is very maybe the last time this group is together.

19) * Colin Powell quite perhaps will be the next secretary of state if Bush is elected.

Both words are used to convey uncertainty. Speakers use maybe and perhaps in order not to commit themselves to certain predictions. Maybe and perhaps come in the middle of the scale between full possibility and zero possibility. They give equal weight to each side. The sentence, 'maybe we can convince her' means there are equal chances to convince or not to convince her. Perhaps is slightly in the positive side. The sentence, 'perhaps we can convince her' implies that there is a little more chance to convince her than not to convince her. Consequently, maybe and perhaps are not preceded by intensifiers because there is nothing to intensify.

Possibly can occur after intensifiers. The basic meaning of possibly indicates a relatively high degree of possibility. Predictions conveyed by possibly imply a good level of positiveness. Therefore, they can be intensified. Possibly can be preceded by a variety of intensifiers. The phrases 'very possibly' and 'quite possibly' are common used phrases in American English. Here are two examples on both of them:

20) In 1517 David Cecil took a 21-year lease of land in Essendine at a rent of $£ 18$. $3 \mathrm{~s}$. $3 \mathrm{~d}$.; not being the freeholder he was not mentioned in the muster, and there is no means of telling whether his global assessment of $£ 46$ at Tinwell embodied the profit of this farm which he very possibly sublet.

21) If Emerson had had the finance to develop a team properly, if his brother had been a better manager and if Emerson himself had not become frustrated as a driver by his car's constant failures and retirements, if, in short, he had got his act together, he would quite possibly have made a first-class constructor and been hailed as a Brazilian Ferrari or Chapman.

Regular adverbs can occur in comparative structures. Sentences such as 'he ran more quickly than I did' or 'she answered less accurately than her classmates' are well-formed sentences. It turns out that the adverbs maybe, perhaps, and possibly cannot occur in such structures. The basic meanings of these words indicate uncertainty, so we cannot compare levels of uncertainty to each other. The following set of examples illustrate this point:

22) * Matsushita Communication Industrial Co. will re-enter the U.S. mobile phone market more possibly next year after a break of nearly five years, President Takashi said Thursday.

23) * I slept an hour, and then less maybe I slept another 30 or 40 minutes in different snippets.

24) * The savvy San Francisco fans are well aware that their chances to see No. 80, a certain Hall of Famer and more perhaps the greatest receiver in NFL history, are dwindling. The 49ers' final two home games are

Sunday against the New Orleans Saints and Dec. 17 against the Chicago Bears.

Another characteristic that maybe, perhaps, and possibly have in common is that they can occur in interrogative sentences to indicate various types of speakers' attitudes concerning anticipating positive or negative answers. The original meaning of the three terms influence the meaning of questions that they occur in. The following examples will illustrate this point:

25) Could you possibly hand that book to me?

26) Could you maybe hand that book to me?

27) Could you perhaps hand that book to me?

In (25) there is an assumption that the addressee is physically able to hand the book and expectation of high level that his response would be positive while (26) and (27) sound weird but they can occur in special cases. The speaker in (25) has 50/50 expectation. It is as if he is saying, 'would you be willing to hand that book to me?' or 'do you have time to hand that book to me?' In (27) there is very little chance for a positive response. The wording of this question indicates that it is asked in an inconvenient situation. It is as if the speaker is interrupting somebody and saying, 'could you by any means hand that book to me?'

Possibly occurs in direct questions with no problems while the occurrence of maybe and perhaps is not as common. However, this is not the case with some types of request that sound like indirect questions where maybe and perhaps can occur perfectly. Here are two examples:

28) Maybe you can help me out?

29) Perhaps you can help me out?

The occurrence of possibly in such request forms seems peculiar and sounds odd. It is highly unusual that a native speaker would utter a sentence like the one in (30):

30) * Possibly you can help me out?

A request of this kind is an appeal that is softened in the form of a question that is marked and characterized by raising intonation at the end of the utterance. Usually people choose a neutral form of request for the purpose of not burdening others. Maybe and perhaps serve this purpose. They are good terms to use in such cases because they don't imply high expectations for positive response from the part of the addressee. Sentences like the one in (28) are more 
informal and occur more frequently than sentences like those in (29) and (30). Sentence (29) is slightly more formal than (28). Sentences like the one in (30) are not common because it is a request that implies a 'yes' answer. Using possibly in indirect questions is weird because possibly is too positive to be used as a terms to hedge a request.

Another interesting characteristic that maybe, perhaps, and possibly have in common is that they don't occur in imperative sentences. The reason for this observable fact is that the basic meanings of these three terms conflict with the concept of expressing commands. Their basic meanings as hedging terms convey possibility and indicate uncertainty so they cannot be used in commands that should sound too strong and definite. Moreover, studying the use of hedging terms from a sociolinguistic aspect is interesting. Hedging terms in multi-gender conversations are considered polite statements and analyzed as rational strategies designed to save face. Previous research has established that saving face is composed of two needs: the need to be unimpeded in conversation (negative politeness) and the need to be approved of (positive politeness). Face-threatening acts that include interruptions and ignoring selection of other speakers can be diminished by politeness strategies such as hedges, minimal responses, indirect constructions, and tag-questions. Women more often employed politeness strategies to minimize a face-threatening act and to show interest and approval than men (Buikema \& Roeters, 1982).

The following grids summarize the similarities and differences among maybe, perhaps, and possibly.

\begin{tabular}{|c|c|c|c|c|}
\hline & Attribute & Maybe & Perhaps & Possibly \\
\hline \multirow{5}{*}{ 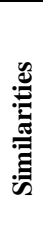 } & Convey possibility & + & + & + \\
\hline & Occur in imperatives & - & - & - \\
\hline & Occur in direct questions & + & + & + \\
\hline & Have a corresponding negative form & _- & _- & - \\
\hline & Occur in comparative structures & _- & - & - \\
\hline \multirow{4}{*}{ 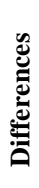 } & Derived from an adjective & - & - & + \\
\hline & Can be rephrased with a cognate word & - & _- & + \\
\hline & Occur initially in request & + & + & _- \\
\hline & Occur after intensifiers & _ & _ & + \\
\hline
\end{tabular}

\section{CONCLUSION}

This paper looked at the terms maybe, perhaps, and possibly in light of their use as hedges and explored the points in which the three terms behave similarly and differently. Even though the three terms maybe, perhaps, and possibly are treated as synonyms in dictionaries and defined in terms of each other, they are different in the sense that they convey different levels of formality, positiveness, and possibility that indicate various categories of un/certainty and likelihood. In a lot of cases these three terms seem interchangeable and can replace one another with no or little change in meaning. In some other cases it is not appropriate to use them interchangeably because of various contextual factors.

The proper use of maybe, perhaps, and possibly, along with other hedging terms, is among the hard points for EFL and ESL students. Part of the difficulty comes from the fact that other languages have different ways to qualify commitment to a claim, express possibility, and convey uncertainty that do not resemble those found in English. Beginners in learning English tend to transfer points from their native languages into English especially because their vocabulary is still in the process of development and their knowledge about the grammatical features, register, or subtle connotations of a word is still limited. Another possible reason why EFL and ESL students make mistakes in using hedges is because hedging terms are not introduced in EFL and ESL textbooks and not taught in classrooms. The result is that L2 students struggle to hedge effectively and make mistakes when expressing un/certainty because they did not understand the specific features behind using particular hedging terms in particular cases.

\section{REFERENCES}

[1] Biber, D., \& Finegan, E. (1989). Styles of stance in English: Lexical and grammatical marking of evidentiality and affect. Textinterdisciplinary journal for the study of discourse, 9(1), 93-124.

[2] Bloor, M., \& Bloor, T. (1991). Cultural expectations and socio-pragmatic failure in academic writing. In P. Adams, B. Heaton, \& P. Howarth, Socio-cultural issues in English for academic purposes (pp. 1-12). London: MacMillan Publishers Ltd

[3] Boncea, I. J. (2014). Hedging patterns used as mitigation and politeness strategies. Annals of the University of Craiova. Series: Philology, English, 2, 7-23.

[4] Brubæk, S. (2013). Pragmatic competence in the EFL classroom: an investigation of the level of pragmatic competence among Norwegian EFL students at the VG1 level (Master's thesis).

[5] Buikema, R. and A. Roeters. (1982). Politeness Strategies in the Interaction of Women and men. Paper presented at the 10th Annual Meeting of the world congress of Sociology. Mexico City.

[6] Crismore, A. (1989). Talking with Readers: Metadiscourse as Rhetorical Act. New York: Peter Lang.

[7] Crompton, P. (1997). Hedging in academic writing: Some theoretical problems. English for specific purposes, 16(4), $271-287$. 
[8] Fraser, B. (2010). Pragmatic competence: The case of hedging. In G. K Kaltenbock, W. Mihatsch, \& S, Schneider (eds.), New approaches to hedging (pp. 15-34). UK: Emerald Group Publishing Ltd.

[9] Halliday, M. A. K. (1994). An Introduction to Functional Grammar (2nd ed). London: Edward Arnold.

[10] Hyland, K. (1994). Hedging in academic writing and EAF textbooks. English for specific purposes, 13(3), 239-256.

[11] Hyland, K. (1998). Hedging in Scientific Research Articles. Amsterdam: John Benjamins.

[12] Hyland, K. (2005). Stance and engagement: A model of interaction in academic discourse. Discourse studies, 7(2), 173-192.

[13] Itani, R. (1995). A relevance-based analysis of Lakoffian hedges: sort of, a typical and technically. UCL Working Papers in Linguistics, 7, 87-105.

[14] Kim, L. C., \& Lim, J. M. H. (2015). Hedging in academic writing-a pedagogically-motivated qualitative study. Procedia-Social and Behavioral Sciences, 197, 600-607.

[15] Lakoff, G. (1972). Hedges: A study of meaning criteria and the logic of fuzzy concepts. In Peranteau. P., J. Levi \& G. Phares (eds.) Papers from the Eighth Regional Meeting of Chicago Linguistic Society. Chicago: Chicago University Press. 183-228.

[16] Martin, J. (2000). Beyond Exchange: APPRAISAL Systems in English. In S. Hunston and G. Thompson (eds.), Evaluation in Text: Authorial Stance and the Construction of Discourse (pp. 142-175). Oxford: Oxford University Press.

[17] Payne T. E. (2011). Understanding English Grammar. Cambridge: Cambridge University Press.

[18] Prince, E. F., Frader, J., \& Bosk, C. (1982). On hedging in physician-physician discourse. Linguistics and the Professions, 8(1), 83-97.

[19] Purpura, J. (2004). Assessing grammar. Cambridge, UK: Cambridge University Press.

[20] Thompson, G. (2001). Interaction in academic writing: Learning to argue with the reader. Applied linguistics, 22(1), 58-78.

[21] Vande Kopple, W. J. (1985). Some explanatory discourse on metadiscourse. College Composition and Communication, 36, 8293.

[22] White, P. R. (2003). Beyond modality and hedging: A dialogic view of the language of intersubjective stance. Text-The Hague Then Amsterdam Then Berlin-, 23(2), 259-284.

[23] Yagız, O. \& Demir, C. (2014). Hedging strategies in academic discourse: A comparative analysis of Turkish writers and native writers of English. Procedia-Social and Behavioral Sciences, 158, 260-268.

[24] Yüksel, H. G., \& Kavanoz, S. (2015). Expressing claim: hedges in English language learners' writing. Journal of teaching and education, 4(1), 263-269.

Fahad Alqurashi is an associate professor at the English department, Umm Al-Qura University, Saudi Arabia. He earned an MA in Linguistics from Indiana State University, 1999, and a PhD in Linguistics from Ball State University, 2005. His research interests include collaborative learning, EFL writing difficulties, and eLearning. 